\title{
Harnessing the diversity of small-scale actors is key to the future of aquatic food systems
}

\author{
Rebecca E. Short ${ }^{1,27 凶}$, Stefan Gelcich ${ }^{2,27}$, David C. Little $\mathbb{B}^{3,27}$, Fiorenza Micheli ${ }^{4,5,27}$, \\ Edward H. Allison ${ }^{6}{ }^{6}$, Xavier Basurto ${ }^{7}$ 7, Ben Belton ${ }^{6,8}$, Cecile Brugere9, Simon R. Bush ${ }^{10}$, Ling Cao"1, \\ Beatrice Crona ${ }^{1,12}$, Philippa J. Cohen ${ }^{6,13}$, Omar Defeo ${ }^{14}$, Peter Edwards ${ }^{15}$, Caroline E. Ferguson ${ }^{16}$, \\ Nicole Franz ${ }^{17}$, Christopher D. Golden ${ }^{18}{ }^{18}$, Benjamin S. Halpern ${ }^{19,20}$, Lucie Hazen ${ }^{4}$, Christina Hicks ${ }^{21}$, \\ Derek Johnson $\mathbb{1}^{22}$, Alexander M. Kaminski ${ }^{3}{ }^{3}$, Sangeeta Mangubhai ${ }^{23}$, Rosamond L. Naylor ${ }^{24}$, \\ Melba Reantaso ${ }^{17}$, U. Rashid Sumaila ${ }^{25}{ }^{25}$ Shakuntala H. Thilsted ${ }^{6}$, Michelle Tigchelaar ${ }^{4}{ }^{4}$, \\ Colette C. C. Wabnitz ${ }^{4,25}$ and Wenbo Zhang ${ }^{26}$
}

Small-scale fisheries and aquaculture (SSFA) provide livelihoods for over 100 million people and sustenance for $\sim 1$ billion people, particularly in the Global South. Aquatic foods are distributed through diverse supply chains, with the potential to be highly adaptable to stresses and shocks, but face a growing range of threats and adaptive challenges. Contemporary governance assumes homogeneity in SSFA despite the diverse nature of this sector. Here we use SSFA actor profiles to capture the key dimensions and dynamism of SSFA diversity, reviewing contemporary threats and exploring opportunities for the SSFA sector. The heuristic framework can inform adaptive governance actions supporting the diversity and vital roles of SSFA in food systems, and in the health and livelihoods of nutritionally vulnerable people-supporting their viability through appropriate policies whilst fostering equitable and sustainable food systems.

oncerns that the global food system is failing to deliver safe, nutritious, sustainable and equitable diets have intensified over the past decade, leading to calls for food system transformation ${ }^{1}$. At the same time, population growth and rising affluence are fuelling demand for more food and for resource-intensive diets. In this landscape of demand and need, visions of what constitutes progress towards a sustainable food system diverge. Agendas for change highlight challenges related to production efficiency, technological innovation, and equity and inclusion ${ }^{2}$.

Recognizing the critical role that small-scale actors play in meeting these challenges requires a deeper understanding of their diverse characteristics and the contributions they make to sustainable and equitable food systems. In this article we draw on the livelihoods and social-ecological systems literature to define the diversity of small-scale fisheries and aquaculture (SSFA) - first, in terms of the suite of strategies used by actors throughout the value chain to meet their objectives and spread economic, social and environmental risk, both across and within geographies and socioenvironmental systems; and second, in terms of how SSFA diversity can impact production, distribution and benefits arising from aquatic food systems.

SSFA produce more than half of the global fish catch and two-thirds of aquatic foods for human consumption, and associated value chains support over 100 million full- and part-time jobs ${ }^{3}$. Nevertheless, the nature and importance of these contributions to food and nutrition security, livelihoods and sustainability remain inadequately recognized by development, food, environment and fisheries policies ${ }^{4}$. We argue one reason for this persistent neglect is that policymakers are challenged by the diversity and dynamism of the SSFA sector. Despite significant advances towards acknowledging SSFA diversity and contributions via efforts such as the FAO's Voluntary Guidelines for Securing Sustainable Small-scale

\footnotetext{
'Stockholm Resilience Centre, Stockholm University, Stockholm, Sweden. ${ }^{2}$ Instituto Milenio en Socio-ecologia Costera \& Center of Applied Ecology and Sustainability, Pontificia Universidad Catolica de Chile, Santiago, Chile. ${ }^{3}$ Institute of Aquaculture, University of Stirling, Stirling, UK. ${ }^{4}$ Stanford Center for Ocean Solutions, Stanford University, Pacific Grove, CA, USA. ${ }^{5}$ Hopkins Marine Station, Stanford University, Pacific Grove, CA, USA. ${ }^{6}$ WorldFish, Batu Maung, Malaysia. ${ }^{7}$ Duke University, Beaufort, NC, USA. ${ }^{8}$ Department of Agricultural, Food and Resource Economics, Michigan State University, East Lansing, MI, USA. ${ }^{9}$ Soulfish Research \& Consultancy, Stillingfleet, UK. ${ }^{10}$ Environmental Policy Group, Wageningen University and Research, Wageningen, The Netherlands. "School of Oceanography, Shanghai Jiao Tong University, Shanghai, China. ${ }^{12}$ Global Economic Dynamics and the Biosphere, Royal Swedish Academy of Science, Stockholm, Sweden. ${ }^{13}$ ARC Centre of Excellence for Coral Reef Studies, James Cook University, Townsville, Queensland, Australia. ${ }^{14}$ Facultad de Ciencias, Montevideo, Uruguay. ${ }^{15}$ School of Environment, Resources and Development, Asian Institute of Technology, Khlong Luang, Thailand. ${ }^{16}$ School of Earth, Energy, and Environmental Sciences, Stanford University, Stanford, CA, USA. ${ }^{17}$ Fisheries Division, Food and Agriculture Organization of the United Nations, Rome, Italy. ${ }^{18}$ Department of Nutrition, Harvard T.H. Chan School of Public Health, Boston, MA, USA. ${ }^{19}$ National Center for Ecological Analysis and Synthesis, University of California, Santa Barbara, CA, USA. ${ }^{20}$ Bren School of Environmental Science and Management, University of California, Santa Barbara, CA, USA. ${ }^{21}$ Lancaster Environment Centre, Lancaster University, Lancaster, UK. ${ }^{22}$ Department of Anthropology, University of Manitoba, Winnipeg, Manitoba, Canada. ${ }^{23}$ Wildlife Conservation Society, Bronx, NY, USA. ${ }^{24}$ Department of Earth System Science and Center on Food Security and the Environment, Stanford University, Stanford, CA, USA. ${ }^{25}$ Institute for the Oceans and Fisheries, University of British Columbia, Vancouver, British Columbia, Canada. ${ }^{26}$ College of Fisheries and Life Science, Shanghai Ocean University, Shanghai, P.R. China. ${ }^{27}$ These authors contributed equally: Rebecca E. Short, Stefan Gelcich, David C. Little, Fiorenza Micheli. ${ }_{e}$-mail: rebecca.short@su.se
} 
Fisheries (SSF Guidelines) ${ }^{5}$, policies affecting the sector typically make unrealistic assumptions of homogeneity and stasis ${ }^{6,7}$. In contrast, as highlighted by the COVID-19 pandemic, responses and adaptive capacity of small-scale actors are highly variable, reflecting their diversity ${ }^{8,9}$.

Failure to address the diverse and dynamic nature of SSFA risks jeopardizing their persistence and the food systems of which they are part. While the viability of SSFA appears key for equitable and sustainable food systems ${ }^{10}$, 'blue economy' narratives ${ }^{11,12}$ grounded in expansion of capital-intensive fisheries, transnational investments and offshore mariculture have gained traction in national and international policy debates. These narratives tend to further homogenize SSFA as dysfunctional, vulnerable and/or marginal, and give preference to industrial over small-scale modes of produc$\operatorname{tion}^{10,11}$. Interactions between industrial fishing and aquaculture interests with SSFA are heterogeneous and can range from cooperation and interdependence ${ }^{13}$ to competing and undermining sustainability with immediate impacts on SSFA viability ${ }^{14}$. It is critical to remove subsidies to industrial concerns, rebalance access to capital and political influence and take steps to counteract simplistic characterizations of SSFA actors, their roles in food systems and how governance reforms may affect, enable or exclude them. As socialecological systems and food sovereignty perspectives argue, SSFA are key to holistic blue food futures ${ }^{15}$, but policymakers need tools that can better incorporate and capitalize on their inherent diversity.

The diversity of SSFA is commonly overlooked, partly due to misrepresentation and contestation over what constitutes 'small-scale' ${ }^{\text {' }}$. Similar to discourses around smallholder agriculture ${ }^{17}$, most analyses of the aquatic sector agree that binary classifications of 'small' and 'large' are inadequate given high geographic and socioeconomic heterogeneity ${ }^{7}$. Rather than pursuing one definition of SSFA, consistent with the SSF Guidelines ${ }^{5}$, this paper aims to prime future analysis to be inclusive of SSFA diversity. We present an innovative heuristic that illustrates the diversity of SSFA actors to examine threats from climate, environmental, socioeconomic and political change, and opportunities to support SSFA viability for more sustainable and equitable food systems.

\section{Results}

We characterized SSFA actors from freshwater and marine fisheries and aquaculture based on 70 case profiles (Extended Data Tables 1 and 2), which span poor to richer or industrialized contexts, and a range of activities by women, men, youths and children. Profiles span value chains, from input procurement to production and harvesting, processing, distribution and trade (Fig. 1 and Extended Data Table 2).

We identified four key dimensions: inputs and assets; markets and demand; management and institutions; and specialization/ diversification (Methods, Fig. 2 and Extended Data Fig. 1). An iterative, inductive process, including two coauthor workshops, was then used to explore diversity and examine case details (Fig. 2). A reductive process was subsequently employed to group characteristics into a manageable and representative core set of eight attributes (Fig. 3). Attributes were then used to describe individual cases (selected examples are presented in Fig. 3). Case profiles were also examined for the relevant threats and opportunities (environmental, economic, social, political) as overarching pressures or levers which alter or enhance an actor's attributes (Fig. 2 and Extended Data Table 3).

The eight attributes, nested within the four dimensions are: (1) level of investment; (2) human and social assets; (3) distance to consumer; (4) product value; (5) formality of institutions/governance; (6) exclusivity of access to the resource; (7) degree of pluriactivity; and (8) diversity of products (Fig. 3). Each attribute represents an intermediate level of abstraction and generalizability of the identified actor and contextual attributes. Attribute combinations provide a way to assess different implications of actor profiles in terms of threats and opportunities, vulnerability or adaptability. In the following sections, we explore these attributes and their diversity, starting at the level of individual actors and activities and expanding to engagement with external actors, markets and influence of governance.

Inputs and assets. Levels of monetary investment and technology are heterogeneous across SSFA (see Table 1, row A for examples). Case profiles show assets ranging from modern processing plants using imported equipment to locally fabricated or home-made gear. The key common element of SSFA is that activities are controlled at a local level by individuals or groups of households. Production inputs also range from self-provisioned or gifted, to investments by other value-chain actors or purchased. Underpinning this variability is a wide range of credit arrangements, from no credit, to informal familial borrowing to formal bank or NGO-facilitated loans, to which access is often mediated by a combination of class, gender, ethnicity, education, age and economic development context. Formal and/or informal access to input provision, information, logistical support, savings, cash or credit helps actors at various points of supply chains to address, cope with or adapt to shocks, market failures and asset shortfalls ${ }^{18}$. Although structures and initiatives that seek to improve access to savings, credit and cash can build adaptive capacity, continued attention to equity, as well as other dimensions of adaptive capacity, remains critical ${ }^{19}$.

The human capital of SSFA actors is also highly variable (Table 1, row B), from basic technical skills adequate to support household food security ${ }^{20}$, to professionalized SSFA producers, traders and processors with formal education or training meeting complex market specifications ${ }^{21}$. Acquiring skills has diverse trajectories from urban-based formal education to local/traditional ecological knowledge and skills employed across value chains. Additionally, case profiles show that the degree of collaboration between actors and across value-chain nodes differs. Some SSFA actors operate individually, while others collaborate through formal or informal agreements, including cooperatives operating in value chains across sectors ${ }^{22}$.

Specialization. SSFA actors specialize in terms of products, activities and engagement through value chains. The degree of specialization is often linked to the ecology of the resource base and the methods used to exploit it (Fig. 1). SSFA might target or cultivate a single species using specialized gear, or use a range of gear and techniques to harvest or cultivate a diversity of species. A focus on more than one species, gear, system, activity and/or product is driven by season, ecology, temporary abundance or market incentives (for example, Table 1, row C). Small-scale fish farmers often utilize polyculture, or engage in activities upstream (for example, trading inputs) or downstream (for example, processing). In much of Asia and sub-Saharan Africa, production of crops and livestock on very small landholdings produces insufficient income and necessitates pluriactivity; aquaculture has often emerged as a secondary activity. Ponds holding fish, doubling as on-farm irrigation water storage, act as a reserve to cover expenses such as school fees ${ }^{23}$ whilst supporting associated horticulture ${ }^{24}$.

SSFA actors engage in aquatic food value chains from year-round to seasonal, from full- to part-time, and trading-off roles within and outside supply chains depending on opportunity or necessity. Both specialization and pluriactivity characterize the livelihood portfolios of SSFA actors (for example, Table 1, row D). Activities may be part of mixed-livelihood portfolios, and involve paid labour or unpaid familial inputs. Age, gender, religion, education and ethnicity are critical factors in the dynamics of how actors may access, enhance and invest their own human capital in livelihoods based around SSFA, with highly variable outcomes for equity and food and nutrition security ${ }^{25}$. 


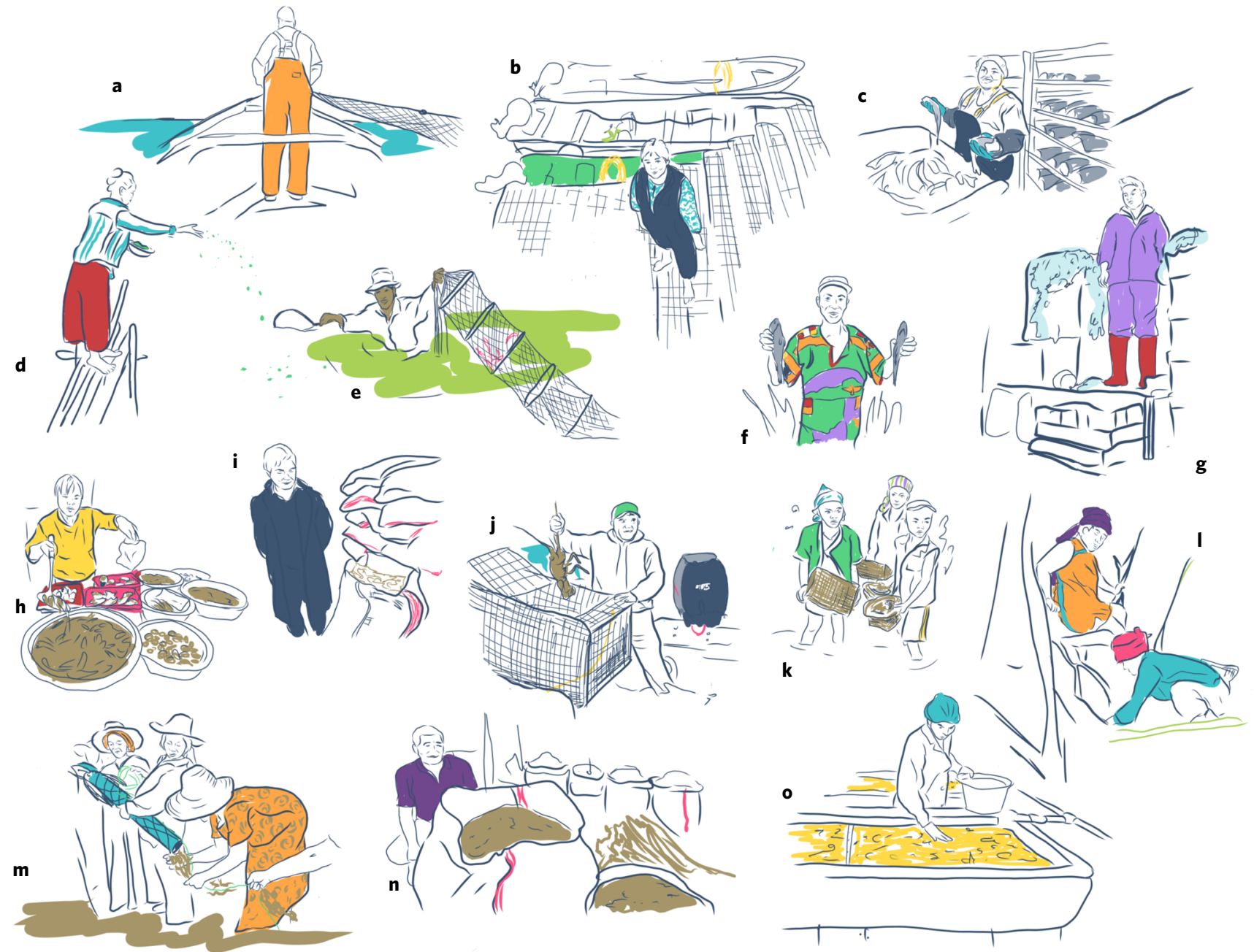

Fig. 1 | Profiles of 15 small-scale actors selected as examples from 70 case profiles representing producers from marine and freshwater fisheries and aquaculture, traders and processors across diverse geographies and demographics. a, Inland Canadian lake-fisher and retail entrepreneur channelling catch to domestic and US markets (Supplementary Table 2, \#SSFA-8). b, Rural Chilean fisherwoman targeting multiple species, including benthic gastropods, in a collective territorial user rights system (\#SSFA-10). c, Processing plant worker from a fishing cooperative in Baja California, Mexico (\#SSFA-45). d, Monosex Nile pond tilapia farmer in Myanmar (\#SSFA-53). e, Mangrove integrated organic shrimp farmer in Vietnam (\#SSFA-65). f, Pluriactive Zambian crop farmer and fisher, who is also a new fish farmer (\#SSFA-67). g, Middleman in Guangdong province, China (\#SSFA-17). h. Chinese businesswoman buying a variety of species wholesale to sell to Shanghai residents (\#SSFA-18). $\mathbf{i}$, Feed producer for the commercial tilapia aquaculture sector in Kenya (\#SSFA-32). j, Lobsterman, finfish and shark fisher from a cooperative in Mexico, geared towards the tourist-based commercial market (\#SSFA-47). k, Child gleaners in Madagascar use handwoven baskets to collect freshwater shrimp, crabs and small fish (\#SSFA-42). I, Indigenous i-Taukei (Fijian) fisherwomen collect mud crabs from mangroves (\#SSFA-23). m, Women seaweed farmers using tubular net technology in Zanzibar, Tanzania (\#SSFA-59). n, Market trader of dried fish in Myanmar's coastal Ayeyarwady region (\#SSFA-52). o, Shellfish processor supplying yellow clams to the Uruguayan luxury restaurant market (\#SSFA-60).

SSFA actors show important differences in the possibilities for diversification. In general, diversification can grant flexibility to an individual's operations, securing them against certain risks and enabling adaptability, as recently demonstrated by responses to the COVID-19 pandemic ${ }^{4,9}$. Flexibility to move between occupations can also provide conditions that support adaptive responses ${ }^{26}$. However, diversification is not always a positive characteristic; it may be an outcome of necessity rather than opportunity ${ }^{27}$. Efficiency or consolidation may be effective in certain operations and contexts, such as processing of high-value resources or transportation logistics. Furthermore, diversification should not undermine the importance of value-chain coordination, much of which is informal within private-sector networks.

A continuum between capture fisheries and aquaculture case profiles highlights important differences between fisheries and aquaculture, particularly for producers. Whereas in some contexts, only low-cost and superficial changes may be required in gear, timing and location of the activity to target a different species for a fisher, aquaculture producers demonstrate serial innovation and adaptation in what and how they farm and how the product gets to market $^{28,29}$.

Engagement with markets and demand. SSFA actors provide aquatic foods to consumers of diverse socioeconomic status, with high-end consumers accessing luxury products through global markets (for example, Table 1, row A), to poorer consumers accessing daily staples from their own harvest, exchange or local markets $^{30}$ (for example, Table 1, row E). High-value products can be accessed through short supply chains, particularly where freshness, water-to-plate or cultural value fetch a price premium (for example, associated with tourism $)^{31}$. Luxury products are also exported after value addition (for example, smoking of sea cucumbers), enabling 

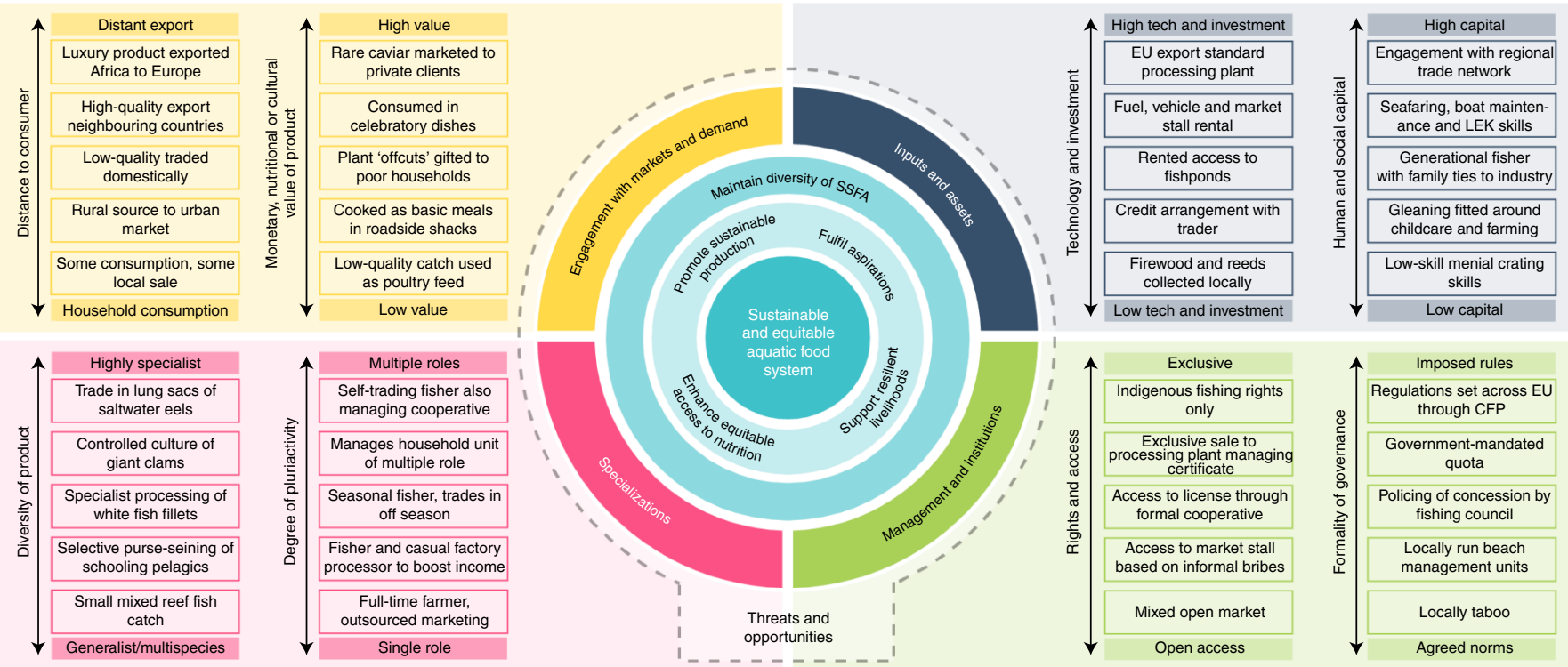

Fig. 2 | An exploration of diversity across SSFA actors and their contribution to a sustainable and equitable aquatic food supply. The key contributions of SSFA to a sustainable and equitable aquatic food supply are shown in the internal rings. The key underpinning dimensions of SSFA actors are shown in the outer ring, and their key attributes as determined by the reductive process are shown on the axes. Diversity within the SSFA sector is demonstrated by example details from case profiles (boxes). CFP, Common Fisheries Policy; LEK, local ecological knowledge.

SSFA actors to benefit from global value chains, although these benefits largely remain inequitably distributed ${ }^{25}$. Lower-value products may also be traded over long distances to meet national and regional demand ${ }^{30}$. Food security is supported directly through processing (drying, salting) and trading or gifting both primary products and by-products locally and indirectly, for example, as livestock feeds ${ }^{32}$.

Market dynamics often reflect local power relations and are commonly underpinned by access to credit. Informal arrangements for cash or provision of consumables by a local patron who also buys and markets the product, typically on a preferential basis, are common (for example, Table 1, row F). The specific dimensions of such patron-client relationships are culturally mediated ${ }^{33}$, and dependence on such relationships is often directly related to the (lack of) availability of family-based credit and accessible, formal credit given by commercial, cooperative or government lenders.

Market dynamics are also sensitive to rapid change in the face of trends and shocks. The COVID-19 pandemic, for example, interrupted supply chains and livelihoods of some, especially those dependent on distant high-value markets ${ }^{34}$. However, new markets and channels-such as online and direct sales-emerged or rapidly expanded to serve consumers in many regions of the world, often in response to faltering or disrupted value chains ${ }^{8,9}$.

Supporting the development of market infrastructure has proven critical for SSFA actors in many contexts, especially where they reduce concentration of market power. Rapid growth of small-scale aquaculture in Asia has often been linked to improved market access, often through competitive intermediaries ${ }^{35}$. Exploring the diversity in SSFA shows that those focused on self-provisioning, exchange and/or supplying local markets are likely to have different needs and challenges to those that target international or urban domestic markets. By linking proximity to consumers and the different modes of production, policymakers can more effectively address equity issues.

Case profiles show aquatic foods may have particular cultural importance that transcends their nutritional qualities, including for communities most nutritionally dependent on them, such as Indigenous and marginalized groups ${ }^{36}$. Cultural attachment and the importance of food sovereignty is also evidenced by transfer of consumption preferences among fish-eating diaspora ${ }^{37}$.
Management and institutions. SSFA actors and their activities are governed by management systems and institutions ranging from centralized government control to localized, culturally embedded arrangements (Fig. 2). In some countries and contexts, access and use rights are legally assigned to SSFA actors. In other contexts, local and cultural institutions dictate those rights, in isolation from (or in concert with) formal legal structures (for example, Table 1, row G) ${ }^{38}$. All governance arrangements present opportunities and challenges to equity and inclusion along lines such as class, gender and ethnicity $^{38}$. Exclusive resource access or private ownership characterize some SSFA, while de facto open-access systems support others, with multiple intermediate forms of common access and use rights to land and water falling in between. Open-access regimes, however, can restrict investment, sustainable management and equity (for example, Table 1, row $\mathrm{H}$ ). The agency and inclusion SSFA actors experience in governance arrangements present an important avenue through which to improve food system outcomes ${ }^{22}$. In contrast, imposed governance mechanisms can sometimes prove ineffective or counterproductive ${ }^{39}$.

Cooperative arrangements were common in many case profiles, particularly for fisheries, enabling coordination and innovation through collective action ${ }^{40}$. Similarly, market-based collective institutions, such as metric-based environmental and social standards, can be critical for SSFA actors to gain and retain access to markets ${ }^{41}$.

Any degree of exclusivity and formality in governance will be influenced by levels of enforcement and compliance, which remain extremely variable across SSFA, particularly as their unique characteristics are often underappreciated in risk-benefit assessments and interventions ${ }^{42}$. Some actors may operate in highly controlled systems of intense monitoring, others may be self-compliant or self-policed through commitment to collective action, and others may operate in wholly unmonitored systems. This diversity highlights the need to recognize and address the specific impacts of monitoring and enforcement on SSFA as a key component of designing inclusive, equitable solutions.

\section{Discussion}

Threats and opportunities for action. Based on the case profiles, here we present key threats from climate, environmental, political 


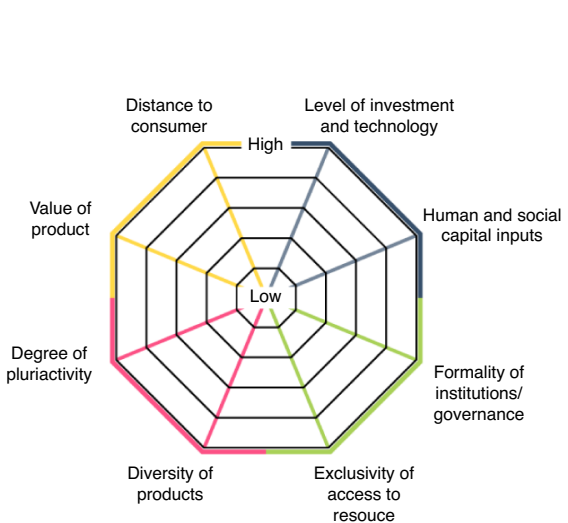

a

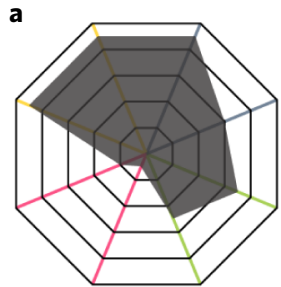

e

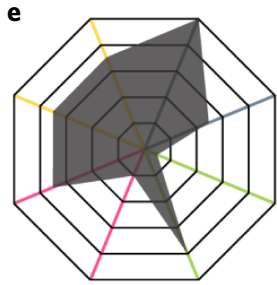

b

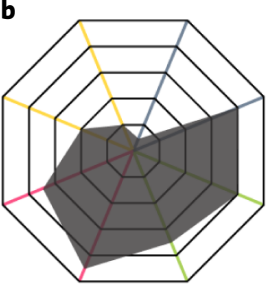

f

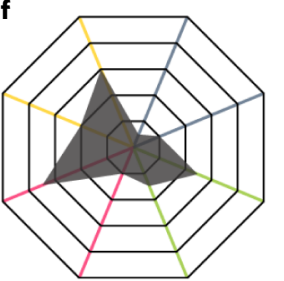

c

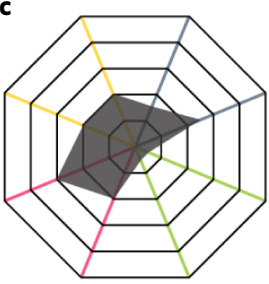

g

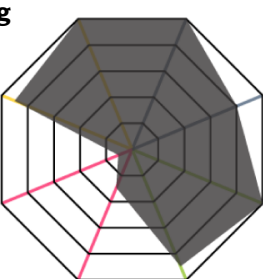

d

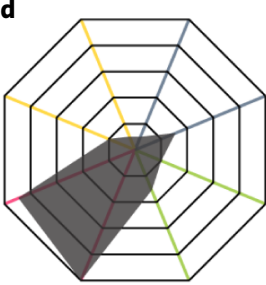

h

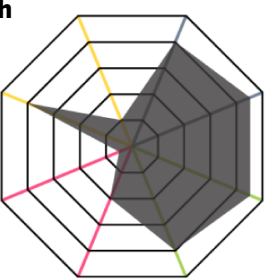

Fig. 3 | Framework of key SSFA attributes. A heuristic framework of key SSFA attributes critical to contextualized policy development is shown in the left-hand panel. a-h, Spider charts exemplifying how the framework may be used to assess SSFA actors in different contexts. Examples represent diverse actors drawn from case studies: high-input intensive tilapia farmer (a); cooperative-supported small-scale freshwater fisher (b); trader and roadside restaurant owner in rural village (c); opportunistic gleaner-agricultural farmer in rural reef fishery (d); trader middleman and creditor (unregulated) serving large urban markets and regional export (e); female part-time fish processor for rural to urban market (f); high-tech processing plant owner serving distant

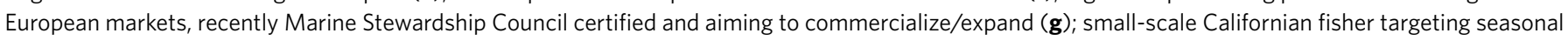
species (multi-gear) in community-supported scheme largely serving local, affluent, subscription-based customers (h).

and socioeconomic change, and opportunities for supporting SSFA viability and equity in the face of these major drivers. Governance failures, poor political representation and power, resource overexploitation, habitat degradation, illegal activities, climate change and COVID-19 emerged as widespread challenges to the viability of SSFA. Dysfunctional institutions, including markets, inequitable access to resources and opportunities, and limited gender and social inclusion are also key threats. Efforts to address these issues can be viewed as investments in supporting sustainable and equitable food systems. Case profiles indicate that SSFA diversity may confer adaptive capacity in the face of threats and opportunities. Greater awareness of the diversity of SSFA actors, within and across socialecological systems, is a prerequisite for appropriate policy development that can support viability in this highly dynamic sector.

Climate change and environmental impacts. Climate change and variability were identified as pervasive threats in case profiles of marine systems (see Extended Data Table 3 for more detail, highlighted by case studies), and in SSFA worldwide ${ }^{43,44}$. In freshwater contexts, water quality, land degradation and loss to urbanization and farming, and changing precipitation also present significant environmental threats ${ }^{45}$. For SSFA actors whose inputs and assets are threatened by climate change-for example, low-tech actors dependent on vulnerable systems (Fig. 3d)-technologies and investments in human and social capital, and in diversification and development of appropriate institutions, offer key opportunities to support their viability ${ }^{26}$.

Shocks to food systems, both market and environmental, can limit local access to aquatic foods and restrict their nutritional contribution. They can also propagate through domestic and international trade networks, impacting prices and availability at multiple scales $^{46}$. Multiple shocks can synergistically combine to affect SSFA actors across whole value chains. Sustainable intensification is a particular challenge for these actors ${ }^{47}$ in increasingly commoditized value chains. Managing water quality to optimize productivity and avoid losses from disease and mass mortalities in the face of increasing climate extremes and uncertainty is a key challenge ${ }^{48}$.

SSFA actors relying on high product diversity but low technology and investment (for example, Fig. 3b) tend to be closely linked to the environment and so are particularly vulnerable to shocks and longer-term environmental change trends. However, our cases also demonstrate high adaptive capacity. For instance, tilapia farmers in northern Zambia, having no access to improved strains used by farmers further south, have based culture on diverse local species adapted to local climate variability. In doing so, local knowledge-exchange networks have evolved, resulting in improved efficiency and circumventing the direct competition of tilapia from southern farmers (Extended Data Table 3). Such adaptation requires agency, flexibility and learning capacities ${ }^{26}$. The development of programmes and policies that remove barriers and provide incentives and resources for diversification, and emphasize inclusive and equitable outcomes, are key strategies for supporting climate adaptation in SSFA.

Some SSFA attributes incur high exposure and sensitivity to shocks. SSFA actors who fish for and sell high-market-value species are exposed to market, transport and infrastructure shocks (for example, Fig. 3g). In addition to addressing logistical or financial exposure, building adaptive capacity in these systems also requires support for social networks and collective learning ${ }^{34}$. Policy developments that incorporate support for the design, implementation, monitoring and institutionalization of climate change adaptation programmes are needed. Supporting adaptive institutions under climate change should be based on a detailed understanding of formal and informal (including traditional) practices-and explicit recognition of previous governance failures. Climate uncertainty can undermine incentives for engaging in long-term planning and commitments to sustainability, or reduce investment in aquaculture development by poorer, more risk-averse actors ${ }^{49}$. Established user-rights-based systems in Chile, Mexico and Uruguay (Fig. 2b,c,o) provide important lessons for what enabling conditions support adaptation to climate change ${ }^{50}$.

Insurance, credit and market mechanisms can provide important protection against extreme events in the dimension of inputs and assets, but they are no substitute for broader adaptive capacity. They may offer little protection to human and social capital. Insurance schemes thus far have only been taken up by large-scale farming operations, through fisheries insurance schemes ${ }^{51}$ Although climate derivatives approaches, which are currently expanding in aquaculture $^{52}$, have the potential to increase the resilience of aquatic food 
Table 1 | Key examples drawn from case profiles to illustrate the diversity of actor characteristics or strategies across the identified SSFA attributes (Fig. 3)

\begin{tabular}{|c|c|c|}
\hline \multicolumn{2}{|c|}{ Attribute } & \multirow[b]{2}{*}{$\begin{array}{l}\text { Example of diversity within small-scale sector } \\
\text { Case studies range from state-of-the-art processing plants with equipment supplying certified fresh yellow } \\
\text { clams to Uruguayan restaurants, to home-made reed baskets by local traders in the Barotse floodplain of } \\
\text { Zambia. } \\
\text { Malawian tilapia farmers may use their agricultural waste as feed, whereas others in Hainan, China may } \\
\text { receive subsidized inputs from large umbrella firms in exchange for exclusive trade agreements. Others, } \\
\text { such as shark fishers in Madagascar or rural-to-urban traders, may need to externally purchase all fuel. } \\
\text { The differential scale of middlemen in small-scale Kenyan systems demonstrates a dichotomy: } \\
\text { low-investment 'Mchuuzis' provide credit in exchange for preferential catch, but high-investment 'Tajiris' } \\
\text { may control boats, equipment and selling power of numerous fishers. }\end{array}$} \\
\hline A & Investment and technology & \\
\hline B & Human and social capital input & $\begin{array}{l}\text { Peer-to-peer asset/knowledge exchange between small-scale and commercial farms in Kerala, India, } \\
\text { community-supported fisheries in the United States developing consumer subscription schemes and } \\
\text { networks such as the African Women Fish Processors and Traders Network are examples of diverse social } \\
\text { cooperation. }\end{array}$ \\
\hline C & Diversity of product & $\begin{array}{l}\text { Abalone divers in Tasmania targeting a specific species with specialized gear and monoculture, monosex } \\
\text { tilapia farming contrast with the reef fisheries of northeastern Madagascar, where net fishers target } \\
\text { whatever they can and traders prioritize volume over specialism in hard-to-reach communities. }\end{array}$ \\
\hline D & Degree of pluriactivity & $\begin{array}{l}\text { Actors engage to a widely variable degree with aquatic food production, from opportunistic mosquito } \\
\text { net fishers fitting the activity around predominant farming and household duties, to full-time dedicated } \\
\text { producers, traders and processors. } \\
\text { Similarly, actors may engage with one or multiple nodes of the aquatic foods value chain; for example, } \\
\text { Vietnamese shrimp farmers may circumvent low prices from processors by directly marketing on social } \\
\text { media, branching out to trade, process and even own restaurants to sell organic shrimp. }\end{array}$ \\
\hline$E$ & Proximity to consumer & $\begin{array}{l}\text { The catch of subsistence mosquito net fishers in Mozambique may go no further than the } \\
\text { household's plates, whereas women seaweed farmers in Tanzania have access to export markets, and } \\
\text { cooperative-owned processing plants in Mexico may be geared towards EU import regulations. }\end{array}$ \\
\hline $\mathrm{F}$ & $\begin{array}{l}\text { Monetary, nutritional and } \\
\text { cultural value of product }\end{array}$ & $\begin{array}{l}\text { Small-scale actors may deal in high-end luxury products such as caviar from sturgeon aquaculture in } \\
\text { Uruguay, or in crabs gleaned from rice paddies in Madagascar with little monetary value that are eaten at } \\
\text { home. } \\
\text { Nutritional contributions are similarly variable. The provision of offcuts to local low-income families by a } \\
\text { Kenyan small-scale tilapia-processing plant may constitute the only source of animal nutrition for such } \\
\text { households, whereas trade of eel lung sacs for Chinese traditional medicine purposes may provide little to } \\
\text { no nutritional value. } \\
\text { Small-scale actors often serve cultural markets, seasonal celebrations and localized speciality preferences; } \\
\text { for example, Seychellois trap fishers target multiple species to suit the local preference for variability, but } \\
\text { also culturally important species, which will sell well. }\end{array}$ \\
\hline G & Formality of governance & $\begin{array}{l}\text { The Comcáac indigenous community gains access to Mexico's fish through formal concessions based on } \\
\text { indigenous rights alongside formal self-governance, in contrast to local customary laws and practices, } \\
\text { which guide access to sea cucumbers in Palau. } \\
\text { Enforcement may rely on relatively high-tech interventions such as phytosanitary testing in processing } \\
\text { plants or electronic monitoring in the high-value Canadian sablefish fishery. Other institutional frameworks } \\
\text { require self-policing; often the case in newly formed co-management efforts in northern Mozambique. }\end{array}$ \\
\hline $\mathrm{H}$ & Exclusivity of access & $\begin{array}{l}\text { Usufruct access in Vietnam means mangrove concessions granted after the war support many small-scale } \\
\text { shrimp farmers; rules on mangrove retention for timber limits expansion. Alternatively, expansion for women } \\
\text { traders in the free markets of Kafr El Sheik, Egypt is limited not by governance, but by competition for space. } \\
\text { Market access may be restricted or controlled in numerous ways; including parent-company-managed } \\
\text { sustainability certifications tying-in many small tilapia farms in Hainan, China. Markets may also be open } \\
\text { and largely unregulated, such as the many rural markets serving communities of sub-Saharan Africa. }\end{array}$ \\
\hline
\end{tabular}

systems to extreme weather events, it is critical that these schemes avoid perpetuating inequalities by favouring larger enterprises to the detriment of poorer or marginalized actors ${ }^{51}$.

Investments in environmental protection and restoration, done collaboratively with actor buy-in and understanding of the full dimensions in which they operate, can deliver significant win-wins. Escalating demand for natural resources, trade-offs with other sectors, and the increasing risks and uncertainties from overexploitation, declines in water quality and disease pose major challenges to effective environmental management for both fishers and farmers and for other value-chain actors. Supporting the diversification of products and activities, continued learning and enabling collective action are key strategies for viable and adaptive SSFA.
Economic shocks, changing demand and globalization impacts. As consumption and demand for aquatic foods increase with rising purchasing power, some species historically produced, traded or consumed within SSFA may be diverted to high-value export markets or local tourism markets ${ }^{53}$ (for example, Fig. 3e). Resulting increased incomes for SSFA actors can pose important trade-offs with local food and nutrition security. SSFA actors, particularly in the rural sector, have limited capacity to influence global market drivers and prevent negative outcomes. Rapidly growing international demand for marine products, for example, has led to industrial harvest of nutritious small pelagics that were previously targeted by artisanal fisheries for local direct human consumption in West Africa ${ }^{54}$. Positive economic and social outcomes may be 
achieved by combining export products with products of low economic value and high nutritional value for local consumption ${ }^{55}$, but such opportunities need diverse targeted policy interventions and strategies ${ }^{47}$ to maintain local food and nutrition security and, at the same time, withstand potential instability of global markets.

The COVID-19 pandemic has brought major disruption to fisheries and aquaculture throughout supply chains, exposing significant vulnerabilities and inequalities ${ }^{8,9,34}$ and highlighting the powerful influence of market dependence. Early in the pandemic, most exports were halted and the majority of domestic markets closed, with major impacts and losses for SSFA actors and supporting socioeconomic systems around the world ${ }^{34}$. Where actors lacked political recognition they could also be excluded from supportive and enabling responses such as curfew exemptions ${ }^{56}$. SSFA responses to the pandemic have been characterized by increased vulnerability but also high resilience. Mobilization of SSFA actors and networks to share information, monitor impacts and transform the crisis into an opportunity has occurred, as has a surge in direct producer to consumer sales (for example, Fig. $3 \mathrm{~h}$ ), e-commerce and local food sharing ${ }^{8,9}$. Such adaptive short-term actions, involving both the products produced/traded and modes of engagement with consumers, have potential to evolve into longer-term adaptive strategies, with as yet uncertain distribution of benefits.

The pandemic has demonstrated the importance of SSFA diversity and recognition as a key element to build adaptive capacity to future economic shocks. Aquatic food systems experience considerable price volatility ${ }^{57}$. Although aquaculture has some ability to schedule production, and thus can decrease price volatilities compared to fishing, such volatility also relates to species and production technology ${ }^{57}$. Case studies signal that pluriactivity and linked fishery and aquaculture systems, such as those developed under territorial user right arrangements, can provide important niche innovations to deal with volatility and economic shocks ${ }^{49}$.

Globalization of SSFA markets also generates competition with industrial operations, both on the water (in the case of fisheries) and in markets, where industrial operations reliably produce cheaper and often high-quality products as an effect of economies of scale throughout value chains. Luxury product, distant market case studies have highlighted the potential impacts of substitutions at a global scale (for example, Fig. 3a). Enhancing diversity in SSFA must consider the complexity of fisheries and aquaculture interactions and how strategies may disrupt long-standing cultural preferences and traditional practices.

Increased participation of SSFA actors in export markets can also mask issues of marginalization and exploitation. Ensuring both traceability and visibility of social impacts is challenging with increasing distance from the end consumer, although use of QR codes by retailers and food service providers show promise in bridging such divides ${ }^{58}$. Supporting SSFA actors at the local scale can be key to ensuring affordable, sustainable and healthy diets. It is important to consider the significant role of women, who remain largely underappreciated drivers of nutritional security and are frequently excluded from land and resource tenure ${ }^{59}$. There are opportunities to embrace 'alternative' systems based on short supply chains for products with strong local identities and local, decentralized approaches to production and processing (for example, Fig. 3c). Diversity, deeply embedded in these food systems, could be supported by policies mandating or incentivizing local retention of SSFA products to ensure food self-sufficiencyfor example, the development or control of local markets and school feeding programs. Market-based approaches that encourage actors to increase the value of products through processing, marketing or certification (for example, Fig. $3 \mathrm{~g}$ ) need to carefully consider such trade-offs on economic, social, environmental and public health outcomes.
Future viability of SSFA. The future of SSFA in all their diverse forms demands that actors are recognized, continue to benefit and remain engaged. The persistence of the small-scale sector suggests that benefits do exist and need to be understood and supported in broader terms than economic value alone. Diversity is essential to SSFA viability and their ability to provide nutritional security; underpinned by individual needs surrounding human and social capital, gender equity and agency, which need to be respected and supported.

First and fundamentally, SSFA actors need to receive sufficient benefits (for example, economic, nutrition, cultural value) from SSFA. There are certain contexts for which being a SSFA actor is tied to poor outcomes with few opportunities to exit and where broader system transformation is necessary ${ }^{60}$. Investments in alternative livelihoods have been largely inadequate and more fundamental structural shifts, such as changes to property rights, that recognize SSFA actors' unique roles and needs are required. Policies that support inclusive relationships with state and/or corporate actors in and beyond the food system may be a key element. Such policies must recognize traditional and indigenous rights, and access rights should support not undermine the rights of indigenous people.

Second, SSFA actors play a key role in food and nutrition security, with globalization often intensifying trade-offs between economic gains from supplying distant markets and the loss of nutritional benefits to local actors. Aquatic foods provide critical support in addressing the triple burden of malnutrition ${ }^{54,61}$. Guidance toward more nutrition-sensitive fisheries governance and aquaculture approaches (for example, polyculture, ecosystem-based solutions) linked to integrative landscape approaches are required to ensure SSFA viability.

Third, human and social capital support the viability and adaptive capacity of SSFA. Our case profiles illustrate that many actors benefit from the economic, nutrition and cultural values delivered through SSFA, and that these attributes can be managed and maintained to align to equity and human well-being objectives of future food systems. Historically, agricultural models have focused on economic upgrading rather than social mobility and resilience ${ }^{23}$. The focus on creating enabling conditions for SSFA actors to adapt and thrive ${ }^{26}$, rather than provision of inputs, is essential for addressing actor-level threats and equity.

Fourth, a high diversity of actors is common within SSFA production systems and value chains and across other sectors. Such diversity may also manifest as pluriactivity and can indicate vulnerability because actors are in some cases forced to take on other functions to cope with variable and uncertain access to assets and opportunities. Maintaining and expanding this diversity and flexibility, and addressing its possible unintended consequences, is key to the viability of SSFA.

Fifth, gender and other aspects of identity are strong determinants of the experiences of different SSFA actors, their contributions to nutritional security and their ability to contribute to overcoming barriers and constraints to better food system outcomes. The roles of women in SSFA remain understudied and undervalued, and the structural disadvantages they face will need to be overcome to achieve equitable and sustainable food systems. The engagement of higher numbers of women in post-harvest and trading is a common phenomenon in aquatic food value chains in many parts of the world, alongside growing recognition of comparatively greater nutritional contributions at the household level ${ }^{59}$. Improving food systems requires a gender lens so as not to perpetuate and exacerbate existing inequalities (for example, intensifying labour burdens $^{62}$ ), and to overcome persistent barriers to women's inclusion.

\section{Conclusion}

The case profiles demonstrate a multitude of benefits associated with greater awareness of and support for the diversity within and across SSFA systems. SSFA actors currently play key roles in families, 
communities and nations. This paper presents a case for their critical centrality in viable aquatic food systems. There are trade-offs that policymakers have to navigate to maintain the benefits from continued engagement of SSFA actors. In particular, meeting the needs of global consumers through large-scale industry poses risks for the cultural integrity, equity, nutritional security and livelihoods provided by SSFA actors. Longer-term actions to redress broader power inequalities, constrain monopolies and support the diversity of SSFA capacities will be critical.

This heuristic framework provides a novel and scalable approach, which can be more fully elaborated subsequently, to specify the diverse and dynamic nature of SSFA in different policy contexts. This contribution aligns closely with the SSF Guidelines ${ }^{5}$, while adding a theoretically informed practical approach to recognize diversity and the suggestion that a similar lens is also relevant to small-scale aquaculture. An appropriate next step would be to extend the inferences enabled by Fig. 3 to other real-world examples. Future research can be deployed in a systematic manner to look at single-food systems, components of food systems, specific regions or countries or other food systems where small-scale actors are key. Deeper consideration of the diversity and characteristics of SSFA actors, through the attributes presented in this framework, will enable policymakers in local national and global fora to ensure that SSFA maintain and expand their role in sustainable and equitable food systems.

\section{Methods}

We characterize SSFA actors from freshwater and marine fisheries and aquaculture based on 70 case profiles provided by this paper's 30 authors (Extended Data Tables 1 and 2). Experts were selected by lead authors, based on contributions to the literature and leadership in international initiatives in the SSFA space (for example, the FAO voluntary guidelines for securing sustainable small-scale fisheries ${ }^{5}$ ) to span diverse geographies and systems, across fisheries and aquaculture and value chains. Despite efforts to comprehensively represent actors, systems and geographies, some gaps remain. To minimize these gaps, we iteratively identified regions and sectors that were underrepresented in workshops, and filled these gaps through additional case studies. Each case profile provided a suite of descriptive variables that depict actors, their roles and contributions in aquatic food systems, as well as the main threats and opportunities they face. The profiles enabled us to explore the diverse roles SSFA actors play in food systems, identifying characteristics that drive their diversity and adaptability.

Analysis proceeded iteratively. Submitted profiles were initially assessed for consistency and completeness within and across cases through iterative discussions across the coauthor group. Any gaps identified were filled through direct requests to specific experts, and literature review. We then adopted a qualitative, empirically grounded and partly inductive approach to characterizing the diversity, threats and opportunities of SSFA.

We assessed and categorized case profiles drawing on archetype analysis approaches $^{63}$ (see Supplementary Text 1 for more details) and the Sustainable Rural Livelihoods Framework ${ }^{64}$, building on this framework through discussion and vetting within the group. The resulting heuristic framework aims to bridge the gap between 'global narratives and local realities ${ }^{93}$ by supporting an intermediate level of abstraction and generalizability of identified actor and contextual attributes. By examining the factors and processes that underlie the diversity through the lens of actors, rather than food systems, the heuristic supports SSFA livelihoods and sustainability through future policy change that accounts for high diversity, rather than being stymied by it.

Reporting Summary. Further information on research design is available in the Nature Research Reporting Summary linked to this article.

\section{Data availability}

The minimum dataset generated during and/or analysed during the current study is available from the corresponding author on reasonable request. A summary table is provided in Supplementary Table 2.

Received: 9 March 2021; Accepted: 9 August 2021; Published online: 15 September 2021

\section{References}

1. Food Security and Nutrition: Building a Global Narrative Towards $2030-A$ Report by the High Level Panel of Experts on Food Security and Nutrition of the Committee on World Food Security (HLPE, FAO, 2020).
2. Bengtsson, M., Alfredsson, E., Cohen, M., Lorek, S. \& Schroeder, P. Transforming systems of consumption and production for achieving the sustainable development goals: moving beyond efficiency. Sustain. Sci. 13, 1533-1547 (2018)

3. The State of World Fisheries and Aquaculture 2020. Sustainability in Action (FAO, 2020); https://doi.org/10.4060/ca9229en

4. Bennett, A. et al. Recognize fish as food in policy discourse and development funding. Ambio 50, 981-989 (2021).

5. Voluntary Guidelines for Securing Sustainable Small-scale Fisheries in the Context of Food Security and Poverty Eradication (FAO, 2015).

6. Gelcich, S., Reyes-Mendy, F., Arriagada, R. \& Castillo, B. Assessing the implementation of marine ecosystem based management into national policies: insights from agenda setting and policy responses. Mar. Policy 92, 40-47 (2018).

7. Johnson, D. S. Category, narrative, and value in the governance of small-scale fisheries. Mar. Policy 30, 747-756 (2006)

8. Bennett, N. J. et al. The COVID-19 pandemic, small-scale fisheries and coastal fishing communities. Coast. Manag. 4, 336-347 (2020).

9. Love, D. et al. Emerging COVID-19 impacts, responses, and lessons for building resilience in the seafood system. Glob. Food Sec. 28 (2021).

10. Farmery, A. K. et al. Food for all: designing sustainable and secure future seafood systems. Rev. Fish Biol. Fish. https://doi.org/10.1007/s11160-02109663-x (2021).

11. Bennett, N. J., Blythe, J., Cisneros-Montemayor, A. M., Singh, G. G. \& Sumaila, U. R. Just transformations to sustainability. Sustainability 11, 3881 (2019).

12. Campbell, L. M. et al. From blue economy to blue communities: reorienting aquaculture expansion for community wellbeing. Mar. Policy 124, 104361 (2021).

13. Pollnac, R. B. In Globalization: Effects on Fisheries Resources (eds Wolfson, L. G., Schechter, M. G. \& Taylor, W. W.) 229-243 (Cambridge Univ. Press, 2007).

14. Crona, B. et al. Sharing the seas: a review and analysis of ocean sector interactions. Environ. Res. Lett. 16, 063005 (2021).

15. Levkoe, C. Z., Lowitt, K. \& Nelson, C. 'Fish as food': exploring a food sovereignty approach to small-scale fisheries. Mar. Policy 85, 65-70 (2017).

16. Smith, H. \& Basurto, X. Defining small-scale fisheries and examining the role of science in shaping perceptions of who and what counts: a systematic review. Front. Mar. Sci. 6, 236 (2019).

17. Woodhill, J., Hasnain, S. \& Griffith, A. Farmers and Food Systems: What Future for Small-Scale Agriculture? (Environmental Change Institute, Univ. Oxford, 2020)

18. Ferrol-Schulte, D., Ferse, S. C. A. \& Glaser, M. Patron-client relationships, livelihoods and natural resource management in tropical coastal communities. Ocean Coast. Manag 100, 63-73 (2014).

19. Osuka, K. et al. Applying a social-ecological systems approach to understanding local marine management trajectories in northern Mozambique. Sustainability 12, 3904 (2020).

20. Béné, C., Hersoug, B. \& Allison, E. H. Not by rent alone: analysing the pro-poor functions of small-scale fisheries in developing countries. Dev. Policy Rev. 28, 325-358 (2010).

21. Pérez-Ramírez, M., Phillips, B., Lluch-Belda, D. \& Lluch-Cota, S. Perspectives for implementing fisheries certification in developing countries. Mar. Policy 36, 297-302 (2012).

22. McCay, B. J. et al. Cooperatives, concessions, and co-management on the Pacific coast of Mexico. Mar. Policy 44, 49-59 (2014).

23. Kaminski, A. M. et al. A review of inclusive business models and their application in aquaculture development. Rev. Aquac. 12, 1881-1902 (2020).

24. Karim, M. Enhancing benefits from polycultures including tilapia (Oreochromis niloticus) within integrated pond-dike systems: a participatory trial with households of varying socio-economic level in rural and peri-urban areas of Bangladesh. Aquaculture 314, 225-235 (2011).

25. Ferguson, C. E. A rising tide does not lift all boats: intersectional analysis reveals inequitable impacts of the seafood trade in fishing communities. Front. Mar. Sci. 8, 625389 (2021).

26. Cinner, J. E. et al. Building adaptive capacity to climate change in tropical coastal communities. Nat. Clim. Change 8, 117-123 (2018).

27. Ellis, F. Household strategies and rural livelihood diversification. J. Dev. Stud. 35, 1-38 (1998)

28. Belton, B., Bush, S. R. \& Little, D. C. Not just for the wealthy: rethinking farmed fish consumption in the Global South. Glob. Food Sec. 16, 85-92 (2018)

29. Belton, B. \& Little, D. The development of aquaculture in central Thailand: domestic demand versus export-led production. J. Agrar. Change 8, 123-143 (2007)

30. Crona, B. I. et al. Towards a typology of interactions between small-scale fisheries and global seafood trade. Mar. Policy 65, 1-10 (2016).

31. Garcia Rodrigues, J. \& Villasante, S. Disentangling seafood value chains: tourism and the local market driving small-scale fisheries. Mar. Policy 74, 33-42 (2016).

32. González-Mon, B. Small-scale fish buyers' trade networks reveal diverse actor types and differential adaptive capacities. Ecol. Econ. 164, 1-11 (2019). 
33. Mialhe, F. et al. Global standardization and local complexity. A case study of an aquaculture system in Pampanga delta, Philippines. Aquaculture 493, 365-375 (2018).

34. Knight, C. J., Burnham, T. L. U., Mansfield, E. J., Crowder, L. B. \& Micheli, F. COVID-19 reveals vulnerability of small-scale fisheries to global market systems. Lancet Planet. Health 4, e219 (2020).

35. Ponte, S., Kelling, I., Jespersen, K. S. \& Kruijssen, F. The blue revolution in Asia: upgrading and governance in aquaculture value chains. World Dev. 64, 52-64 (2014).

36. Cisneros-Montemayor, A. M., Pauly, D., Weatherdon, L. V. \& Ota, Y. A global estimate of seafood consumption by coastal indigenous peoples. PLOS ONE 11, e0166681 (2016).

37. Walker, I. Ntsambu, the foul smell of home: food, commensality and identity in the Comoros and in the diaspora. Food Foodways 20, 187-210 (2012).

38. Jentoft, S., McCay, B. \& Wilson, D. Social theory and fisheries co-management. Mar. Policy 22, 423-436 (1998).

39. Jones, L. et al. Responding to a Changing Climate: Exploring How Disaster Risk Reduction, Social Protection and Livelihoods Approaches Promote Features of Adaptive Capacity (Overseas Development Institute, 2010).

40. Gelcich, S., Guzman, R., Rodríguez-Sickert, C., Castilla, J. C. \& Cárdenas, J. C. Exploring external validity of common pool resource experiments: Insights from artisanal benthic fisheries in Chile. Ecol. Soc. 18, art2 (2013).

41. Micheli, F. et al. A system-wide approach to supporting improvements in seafood production practices and outcomes. Front. Ecol. Environ. 12, 297-305 (2014).

42. Oyanedel, R., Gelcich, S. \& Milner-Gulland, E. J. A synthesis of (non-) compliance theories with applications to small-scale fisheries research and practice. Fish Fish. 21, 1120-1134 (2020).

43. Belton, B., Little, D. \& Grady, K. Is responsible aquaculture sustainable aquaculture? WWF and the eco-certification of Tilapia. Soc. Nat. Resour. 22 840-855 (2009).

44. Defeo, O. et al. Impacts of climate variability on Latin American small-scale fisheries. Ecol. Soc. 18, 4 (2013).

45. Barange, M. et al. Impacts of Climate Change on Fisheries and Aquaculture: Synthesis of Current Knowledge, Adaptation and Mitigation Options FAO Fisheries and Aquaculture Technical Paper 627 (FAO, 2018).

46. Gephart, J. A., Rovenskaya, E., Dieckmann, U., Pace, M. L. \& Brännström, Å. Vulnerability to shocks in the global seafood trade network. Environ. Res. Lett. 11, 035008 (2016).

47. Little, D. C. et al. Sustainable intensification of aquaculture value chains between Asia and Europe: a framework for understanding impacts and challenges. Aquaculture 493, 338-354 (2018).

48. Reid, G. et al. Climate change and aquaculture: considering biological response and resources. Aquac. Environ. Interact. 11, 569-602 (2019).

49. Gelcich, S. \& Donlan, C. J. Incentivizing biodiversity conservation in artisanal fishing communities through territorial user rights and business model innovation: TURFs, innovation and biodiversity benefits. Conserv. Biol. 29, 1076-1085 (2015).

50. Defeo, O. et al. Co-management in Latin American small-scale shellfisheries: assessment from long-term case studies. Fish Fish. 17, 176-192 (2016).

51. Sainsbury, N. C., Turner, R. A., Townhill, B. L., Mangi, S. C. \& Pinnegar, J. K. The challenges of extending climate risk insurance to fisheries. Nat. Clim. Change 9, 896-897 (2019).

52. Little, L. R., Hobday, A. J., Parslow, J., Davies, C. R. \& Grafton, R. Q. Funding climate adaptation strategies with climate derivatives. Clim. Risk Manag. 8, 9-15 (2015)

53. Wabnitz, C. C. C., Cisneros-Montemayor, A. M., Hanich, Q. \& Ota, Y. Ecotourism, climate change and reef fish consumption in Palau: benefits, trade-offs and adaptation strategies. Mar. Policy 88, 323-332 (2018).

54. Hicks, C. C. et al. Harnessing global fisheries to tackle micronutrient deficiencies. Nature 574, 95-98 (2019).

55. Kurien, J. Responsible Fish Trade and Food Security (FAO Fisheries Technical Paper 456 (FAO, 2005).

56. Fiorella, K. J. et al. Small-scale fishing households facing COVID-19: the case of Lake Victoria, Kenya. Fish. Res. 237, 105856 (2021).
57. Dahl, R. E. \& Oglend, A. Fish price volatility. Mar. Res. Econ. 29, 305-322 (2014)

58. Djelantik, A. A. A. S. K. \& Bush, S. R. Assembling tuna traceability in Indonesia. Geoforum 116, 172-179 (2020).

59. Harper, S., Zeller, D., Hauzer, M., Pauly, D. \& Sumaila, U. R. Women and fisheries: contribution to food security and local economies. Mar. Policy 39, 56-63 (2013).

60. Béné, C. \& Friend, R. M. Poverty in small-scale fisheries: old issue, new analysis. Prog. Dev. Stud 11, 119-144 (2011).

61. Gephart, J. A. et al. Scenarios for global aquaculture and its role in human nutrition. Rev. Fish. Sci. Aquac. 29, 122-138 (2021).

62. Blackden, C. M. \& Wodon, Q. Gender, Time Use, and Poverty in Sub-Saharan Africa Working Paper No. 73 (World Bank, 2006).

63. Oberlack, C. et al. Archetype analysis in sustainability research: meanings, motivations, and evidence-based policy making. Ecol. Soc. 24, 26 (2019).

64. Carney, D. Sustainable Rural Livelihoods: What Contribution Can We Make? (Department for International Development, 1998).

\section{Acknowledgements}

This paper is part of the Blue Food Assessment (BFA) (https://www.bluefood.earth/), a comprehensive examination of the role of aquatic foods in building healthy, sustainable and equitable food systems. The BFA was supported financially by the Builders Initiative, the MAVA Foundation, the Oak Foundation and the Walton Family Foundation, and has benefited from the intellectual input of the wider group of scientists leading other components of the BFA. This work was also undertaken as part of the CGIAR Research Program (CRP) on Fish Agri Food Systems (FISH), led by WorldFish and contributing to the WorldFish 2030 Research and Innovation Strategy: Aquatic Foods for Healthy People and Planet and the One CGIAR. The programme is supported by contributors to the CGIAR Trust Fund. Other acknowledgements towards this collaboration go to: ANID-Iniciativa Cientifica Milenio ICN2019_015, ANID-PIA/Basal FB 0002 (for S.G.); the GAIN project has received funding from the European Union's Horizon 2020 research and innovation programme under grant agreement number 773330 (for D.C.L.); National Science Foundation DEB121244 and BioOce 1736830 (for F.M.); the Nippon Foundation Ocean Nexus Program, Earthlab, University of Washington (for E.H.A.); the Erling-Persson Family Foundation (for B.C.); the Inter-American Institute for Global Change Research (for O.D.); the National Science Foundation (CNH 1826668) and the John and Katie Hansen Family Foundation (for C.D.G.); the European Research Council (grant number 759457) (for C.H.); and the iFISH programme from China Blue Sustainability Institute (for W.Z.).

\section{Author contributions}

R.E.S., S.G., D.C.L. and F.M. were responsible for conceptualization, methodology, formal analysis, investigation, data curation, writing (original draft), writing (review and editing), visualization, project administration and supervision. L.H. was responsible for formal analysis, data curation, writing (review and editing), visualization and project administration. E.H.A., X.B., B.B., M.R., C.B., S.R.B., L.C., B.C., P.J.C., O.D., P.E., C.E.F., N.F., C.D.G., B.S.H., C.H., D.J., A.M.K., S.M., R.L.N., U.R.S., S.H.T., M.T., C.C.C.W. and W.Z. were responsible for conceptualization, investigation and writing (review and editing).

\section{Competing interests}

The authors declare no competing interests.

\section{Additional information}

Supplementary information The online version contains supplementary material available at https://doi.org/10.1038/s43016-021-00363-0.

Correspondence and requests for materials should be addressed to Rebecca E. Short. Peer review information Nature Food thanks Gianluca Brunori, Tim Gray and Kristen Lowitt for their contribution to the peer review of this work.

Reprints and permissions information is available at www.nature.com/reprints. Publisher's note Springer Nature remains neutral with regard to jurisdictional claims in published maps and institutional affiliations.

(C) The Author(s), under exclusive licence to Springer Nature Limited 2021, corrected publication 2021 


\section{Reporting Summary}

Nature Research wishes to improve the reproducibility of the work that we publish. This form provides structure for consistency and transparency in reporting. For further information on Nature Research policies, see our Editorial Policies and the Editorial Policy Checklist.

\section{Statistics}

For all statistical analyses, confirm that the following items are present in the figure legend, table legend, main text, or Methods section.

n/a Confirmed

Х $\square$ The exact sample size $(n)$ for each experimental group/condition, given as a discrete number and unit of measurement

Х $\square$ A statement on whether measurements were taken from distinct samples or whether the same sample was measured repeatedly

$\triangle$ The statistical test(s) used AND whether they are one- or two-sided

Х $\square$ Only common tests should be described solely by name; describe more complex techniques in the Methods section.

Х $\square$ A description of all covariates tested

Х $\square$ A description of any assumptions or corrections, such as tests of normality and adjustment for multiple comparisons

$\varnothing \square$ A full description of the statistical parameters including central tendency (e.g. means) or other basic estimates (e.g. regression coefficient)

$\triangle \square$ AND variation (e.g. standard deviation) or associated estimates of uncertainty (e.g. confidence intervals)

$\bigotimes \square \begin{aligned} & \text { For null hypothesis testing, the test statistic (e.g. } F, t, r \text { ) with confidence intervals, effect sizes, degrees of freedom and } P \text { value noted } \\ & \text { Give } P \text { values as exact values whenever suitable. }\end{aligned}$

\ $\square$ For Bayesian analysis, information on the choice of priors and Markov chain Monte Carlo settings

Х $\square$ For hierarchical and complex designs, identification of the appropriate level for tests and full reporting of outcomes

\ $\square$ Estimates of effect sizes (e.g. Cohen's $d$, Pearson's $r$ ), indicating how they were calculated

Our web collection on statistics for biologists contains articles on many of the points above.

\section{Software and code}

Policy information about availability of computer code

Data collection no software was used

Data analysis no software was used

For manuscripts utilizing custom algorithms or software that are central to the research but not yet described in published literature, software must be made available to editors and reviewers. We strongly encourage code deposition in a community repository (e.g. GitHub). See the Nature Research guidelines for submitting code \& software for further information.

\section{Data}

Policy information about availability of data

All manuscripts must include a data availability statement. This statement should provide the following information, where applicable:

- Accession codes, unique identifiers, or web links for publicly available datasets

- A list of figures that have associated raw data

- A description of any restrictions on data availability

The datasets generated during and/or analyzed during the current study are available from the corresponding author on reasonable request. 


\section{Field-specific reporting}

Please select the one below that is the best fit for your research. If you are not sure, read the appropriate sections before making your selection.
Life sciences
Behavioural \& social sciences
Ecological, evolutionary \& environmental sciences

For a reference copy of the document with all sections, see nature.com/documents/nr-reporting-summary-flat.pdf

\section{Behavioural \& social sciences study design}

All studies must disclose on these points even when the disclosure is negative.

Study description

Research sample

Sampling strategy

Data collection

Timing

Data exclusions

Non-participation

Randomization
This is a perspective piece, though it draws on case studies these are produced by the study authors and no external data collection or people were involved

75 case studies

Expert knowledge elicitation

Electronic template circulated to authors

$16 / 07 / 2020-20 / 10 / 2020$

3 cases were excluded due to being related to governance groups rather than actors, which was the focus of the study

na

na

\section{Reporting for specific materials, systems and methods}

We require information from authors about some types of materials, experimental systems and methods used in many studies. Here, indicate whether each material, system or method listed is relevant to your study. If you are not sure if a list item applies to your research, read the appropriate section before selecting a response.

Materials \& experimental systems

\begin{tabular}{|c|c|}
\hline $\mathrm{n} / \mathrm{a}$ & Involved in the study \\
\hline Х & Antibodies \\
\hline Х & Eukaryotic cell lines \\
\hline$\bigotimes$ & Palaeontology and archaeology \\
\hline$凶$ & Animals and other organisms \\
\hline$\bigotimes$ & Human research participants \\
\hline$\bigotimes$ & Clinical data \\
\hline Х & $\square$ Dual use research of concern \\
\hline
\end{tabular}

\author{
Methods \\ $\mathrm{n} / \mathrm{a}$ Involved in the study \\ $\triangle \square$ ChIP-seq \\ Х $\square$ Flow cytometry \\ \ $\square$ MRI-based neuroimaging
}

